\section{Baltimore's unanswered questions}

SIR - Rather than replying in detail to David Baltimore's open letter to me (Nature 353, 9; 1991), I would suggest that interested readers compare his letter with my Commentary article (Nature 352, 183; 1991). The disconnection is nearly total. I stated: "Reviewing the case strictly from Baltimore's published account reveals at least four lapses .

Baltimore counters with: ". . . your verdicts are . . . based mainly on the unsubstantiated, and often refuted, allegations of one participant . . .". My statement is true, his is not. In passing, it is interesting to note Baltimore's changing views of the "one participant, Dr O'Toole". Only four months ago he wrote of her: "I have tremendous respect for $\mathrm{Dr}$ O'Toole . . . and I believe that her expressions of concern were proper and appropriate, and her motives were pure" (Nature 351, 94; 1991).

Here is another example. I stated that "until the final OSI report is released, we will not known the extent to which the opposing views of the authors of the Cell paper will have affected final judgements". Therefore I did not use any of the findings of the draft report in my argument. Yet Baltimore rebukes me for using "a leaked, confidential draft of a government report as a basis for definitive judgements about the acts of others".

Against my claim that his own testimony in this case shows a regrettable departure from normal standards, he replies that: "I believe that my science — including the Weaver et al. paper - is done with vigour and criticality" - a claim that stands in contradiction to his retraction of the paper. One can judge which of these views is more nearly correct by noting Ptashne's demonstration (see below) that essential data in the Weaver et al. paper is either nonexistent or undecipherable. Baltimore then goes on to say that the only way to judge his paper is to demonstrate whether or not the data are reliable. But the presentation of the 'data' is such as to prevent the application of this test.

The claim is then made that "much published evidence ... support [s his] paper's results in remarkable detail". However, an examination of this evidence shows that it is not at all evident that the six papers referenced provide any support at all. But there is a deeper criticism of Baltimore's claim that all is well if his conclusions are ultimately shown to be correct. The scientific literature would become irredeemably corrupted if this became accepted practice. The essential standard is that the evidence presented in a scientific paper is the bedrock on which interpretations and conclusions are built. If this connection is violated so that speculations drawn depend on subsequent investigations to prove right or wrong, then the reporting of research would be reduced to a lottery.

The missing RNA band is dismissed with "its existence was not of significance to the paper". However, if the band was visible on the gel, were the authors not obliged to state this in the paper and comment on its significance? If not, does this not lower existing standards by affirming that unwelcome data need not be presented or mentioned?

The part of my Commentary concerned with Baltimore dealt almost entirely with criticizing his behaviour and urging that it should not contribute to debasing past standards of conducting and reporting reseach. In his reply to me, Baltimore ignores this central theme and insists that he has always abided by the higher standards. This is the ultimate disconnection: alas it shows no sign of being bridged.

Harvard University,

PAUL DOTY Cambridge, Massachusetts 02138, USA

SIR - In his response to my letter of 11 July (Nature 352, 101; 1991), Erik Selsing (Nature 352, 657; 1991) says the "central claim" of Weaver et al. (Cell 45, $247-259$; 1986) is "most directly" supported by data describing idiotypepositive antibodies whose heavy chains are $\gamma$ and $\alpha$ (as distinguished from $\mu$, the transgene-encoded antibody). Indeed, the presence of such molecules significantly above the level found in control animals would support the central claim, provided they were not encoded by recombinants formed between the transgene and endogenous genes. But where are these essential data?

Initially, referring to Table 2 of their paper, Weaver et al. wrote on page 250 that: "Of the 172 idiotype-positive hybridomas, only 53 were IgM secretors. The remaining 119 clones produced other Ig heavy chain isotypes, the majority being $\gamma_{2 B}$ (data not shown)." Then, in a letter of correction (Cell 55, 541; 1988), the authors said: "Again relating to Table 2, the non-IgM-containing wells were referred to as 'mostly $\gamma_{2 \mathrm{~B}}$ ' in the text. In fact, the data showing that a majority were $\gamma$ (not necessarily $\gamma_{2 \mathrm{~B}}$ ) came from separate experiments, not the ones depicted in Table 2."

Although the authors themselves do not say to which experiments they are referring, Selsing says that the crucial isotyping results are presented in Table 3. This table, both in the original and in the version published in a further correcisotype of the immunoglobulin $\mathrm{M}$ ( $\operatorname{IgM})$ tion (Cell 57, 515; 1989), lists 34 hybridomas and states, for 30 of these, whether the secreted antibody heavy chain is $\gamma, \alpha$ or $\mu$; four are listed as not determined. Fifteen are claimed to have $\gamma$ heavy chains - but 15 is hardly a "majority of" the 119 mentioned in the original text. One is left wondering whether Table 3 does in fact contain the isotyping results referred to in the correction of 1988.

Nevertheless, as suggested by Selsing, perhaps the crucial isotyping data are contained in Table 3; if so, we are faced with the problem that the paper does not tell what experiment was actually done. For example, are all the listed hybridomas idiotype-positive? Which of the two assays that detect idiotype-positive molecules, described in the methods section, was used - or were different methods used for different entries? Are we to assume that each entry corresponds to a cloned hybridoma producing a single species of antibody and, if so, where is the evidence? Where are the corresponding results for control mice?

At the time its draft report was written, the Office of Scientific Integrity evidently was not able to resolve ambiguities in Table 3 despite (presumably) a far more extensive analysis. Referring to the results of isotype assays (ELISA) reported in Table 3 , the draft report (p. 110) says: "It appears that the choice is between believing the serological methods employed were seriously inadequate or the ELISA was mislabelled and misrepresented."

We are considering the crucial experiment, reported more than five years ago - and challenged soon thereafter followed by two published corrections. One would have thought there had been ample opportunity for the authors to have clarified the issues. If Selsing has satisfactory answers to these essential questions, why aren't they available to the rest of us?

Harvard University,

MARK PTASHNE

Cambridge, Massachusetts 02138, USA

\section{Energy costs}

SIR — You fear that rising energy prices would hurt the economy (Nature 352, $649,1991)$. A look at the facts may be useful. Among the countries with the biggest industrial output energy prices from 1975 to 1990 were highest in Japan, followed by (West) Germany, for United States and finally by the Soviet Union all with a wide margin.

Institut for Europáische

Umwenpolitk eV

Aloys-Schuntze-Strasse 6 ,

D-5300 Bonn 1,

Germany 